Michael McGuire, Editor

Maria Cucciniello

Bocconi University, Italy
Gregory A. Porumbescu

Northern Illinois University

Stephan Grimmelikhuijsen

Utrecht School of Governance, The Netherlands

\section{Research Synthesis}

Maria Cucciniello is assistant professo in the Department of Policy Analysis and Public Management at Bocconi University in Milan, Italy. She holds a PhD in management from the University of Edinburgh, United Kingdom. Her research focuses on transparency in government, innovation in the public and health care sectors, coproduction of public services, and the impact of technology on the public and health care sectors.

E-mail: maria.cucciniello@unibocconi.it

Gregory A. Porumbescu is assistant professor in the Department of Public Administration at Northern Illinois University. His research focuses on public sector transparency, e-government, and citizen perceptions of government. His work has appeared in journals such as Public Administration Review, Journal of Public Administration Research and Theory, and American Review of Public Administration. E-mail: gporumbescu@gmail.com

Stephan Grimmelikhuijsen is assistant professor in the Utrecht School of Governance of Utrecht University, The Netherlands. He is interested in public sector and court transparency, citizen attitudes, legitimacy, behavioral public administration, and experimental methodology. His work has appeared in journals such as Public Administration, Public Administration Review, and Journal of Public Administration, Research and Theory. E-mail:s.g.grimmelikhuijsen@uu.nl
Public Administration Review Vol. 77, Iss. 1, pp. 32-44. @ 2016 by The American Society for Public Administration. DOI: 10.1111/puar. 12685

\title{
25 Years of Transparency Research: Evidence and Future Directions
}

Abstract: This article synthesizes the cross-disciplinary literature on government transparency. It systematically reviews research addressing the topic of government transparency published between 1990 and 2015. The review uses 187 studies to address three questions: (1) What forms of transparency has the literature identified? (2) What outcomes does the literature attribute to transparency? and (3) How successful is transparency in achieving those goals? In addressing these questions, the authors review six interrelated types of transparency and nine governance-and citizen-related outcomes of transparency. Based on the findings of the analysis, the authors outline an agenda for future research on government transparency and its effects that calls for more systematically investigating the ways in which contextual conditions shape transparency outcomes, replicating studies with varying methodologies, investigating transparency in neglected countries, and paying greater attention to understudied claims of transparency such as improved decision making and management.

\section{Practitioner Points}

- Government transparency is no cure-all and does not always have positive outcomes.

- Transparency is effective at achieving certain outcomes, such as increasing participation, improving financial management, and reducing corruption.

- Transparency is less effective at engendering trust in and legitimacy of government.

- Our analysis suggests that government transparency "works" under some conditions but not under others. What these conditions are needs further investigation.

$\mathrm{O}$ ver the course of the past two decades, there have been many attempts to bolster transparency at every level of government. These attempts have been guided by a long-standing expectation that enhancing transparency will bring about improvements to the quality of government (Kosack and Fung 2014, 84; Piotrowski 2008; Roberts 2006). Accordingly, governments now view transparency as a means of achieving an array of objectives, ranging from fostering greater trust in government to reducing public corruption and improving financial performance (Benito and Bastida 2009; Bertot, Jaeger, and Grimes 2010; Welch, Hinnant, and Moon 2005; Worthy 2010).

Despite such optimism, scholars have recently questioned the extent to which transparency is actually capable of fulfilling the range of objectives commonly ascribed to it (Etzioni 2010, 2014). In general, what this expanding line of inquiry illustrates is that the effects of transparency are much less pronounced than conventional wisdom suggests. Indeed, as a number of empirical assessments have found, transparency's effects are often limited and differ according to a number of factors such as area of government, policy domain, and citizen characteristics (de Fine Licht 2014; de Fine Licht et al. 2014; Grimmelikhuijsen and Meijer 2014; Porumbescu 2015b). Others have argued that efforts to enhance transparency often result in more harm than good, reasoning that continual efforts to enhance transparency have fueled polarization, indecision, and, ultimately, dysfunction in government (Grumet 2014).

In response to such challenges, a growing number of scholars and practitioners are beginning to debate the role of transparency in the practice of public administration. While few on either side of this debate would go so far as to actually support general reductions in transparency, what is quickly coming into focus is a need to think more systematically about how transparency can be used for better governance. At present, more transparency is often indiscriminately proffered as a solution to the gamut of challenges facing governments. Yet, like any instrument, transparency is not without its limits-inevitably, transparency is well suited to 
address certain issues and poorly suited to address others. From this perspective, much of the debate over the role of transparency in the practice of public administration can be attributed to confusion over just what transparency can do and, perhaps more importantly, what it cannot (Meijer 2009; Roberts 2015). In this article, we focus on government transparency as an instrument to achieve other outcomes, such as increased trust or less corruption.

Despite this long-standing debate about the potential outcomes of increased government transparency, scholarly attention has been disjointed, emanating from various disciplines and looking at various types of transparency and types of transparency outcomes. The first goal of this article, therefore, is to disentangle this confusion over the effects of transparency. To set an agenda for future research, we present a cross-disciplinary systematic literature review of government transparency published from 1990 to 2015. The second goal is to distill emergent themes from a rapidly evolving body of transparency literature. The insights provided by a systematic overview help identify where gaps exist in our understanding of how transparency relates to different facets of government and, thereby, contribute to the establishment of a more cohesive transparency research agenda.

Our analysis is guided by three specific research questions:

1. What forms of government transparency are identified in the literature?

2. What outcomes has the literature attributed to government transparency?

3. What outcomes does government transparency tend to be (un)successful in achieving?

The systematic literature review yielded a set of 187 records published between 1990 and 2015. In reporting the systematic review, we adhere to the widely used Preferred Reporting Items for Systematic Reviews and Meta-Analyses (PRISMA, see online appendix 1) (Liberati et al. 2009). Based on our review, we find that the literature identifies six forms of government transparency. We also find that the literature included in our analysis identifies nine distinct goals associated with greater transparency. However, the results of empirical assessments of the relationships between transparency and the different goals attributed to it are often far from consistent. Based on these findings, we conclude by outlining a future research agenda.

\section{Methodological Approach}

To our knowledge, no systematic literature reviews have examined transparency outcomes. ${ }^{1}$ As a result, we lack a structured and comprehensive accounting of research on how the public sector is using transparency and to what effect. From a methodological standpoint, a systematic literature review is a desirable method for providing a comprehensive overview of this area of research because of its explicit, rigorous, and transparent procedures (Cooper 2010), which, in turn, render reviews easily replicated (Tranfield, Denyer, and Smart 2003). We outline the methods that were used to identify articles included for analysis in this study next.

In this study, three strategies were used to identify eligible articles (Cooper 2010). First, we searched two online databases: ISI
Web of Knowledge and Scopus. This was done to ensure that a broad spectrum of research on transparency was included for consideration. The search terms we used were "transparency and government," "public sector transparency," "administrative transparency," and "transparent government." This search generated more than 3,300 studies; it was last conducted in November 2015.

Second, this broad search strategy was supplemented by a manual review of 13 journals in the fields of public administration, public management, and e-government and an analysis of 10 books. We examined key journals on a journal-by-journal basis. To do this, we first drafted a list of journals to be included in the analysis. We then consulted with experts on the topic of transparency to ensure that all relevant journals that publish regularly about transparency were included while also asking them for input on relevant studies. ${ }^{2}$ They identified two more journals to be included in the review (Information Polity and Government Information Quarterly). We received the last expert e-mail in October 2015. Based on the initial list of journals that was compiled, coupled with the recommendations from experts, 13 journals were included for individual review. ${ }^{3}$ The last search was conducted in November 2015 and generated 315 possible studies for inclusion.

Third, to supplement the journal articles retrieved, we also searched Google Books for relevant monographs on this topic using the same keywords that were used in the earlier searches. In total, 10 monographs were included; the last search was conducted in November 2015.

\section{Eligibility Criteria}

After establishing a list of eligible journals and books, we determined eligibility criteria - a key step in conducting a systematic literature review is establishing clear eligibility criteria. The criteria were designed to ensure that high-quality relevant work was included.

Studies from our original searches were included in the systematic review if they met all of the following eligibility criteria:

- Topic: Abstracts or titles of articles included any of the following terms: "transparency and government," "public sector transparency," "administrative transparency," any "transparent government." It is important to note that the term "open government" was not included for analysis because it is generally believed to be a broader construct reflecting various dimensions, one of which is transparency (e.g., Meijer, Curtin, and Hillebrandt 2012; Roberts 2012). For similar reasons, we also did not search for "freedom of information act (FOIA)," "right to know," or "access to information." However, if a given article included one of the aforementioned terms plus one of the designated search terms, the article would be included for analysis. Narrowing our search in this way helped ensure that the articles included for analysis possessed direct implications for the study of transparency. However, given the interrelatedness of the aforementioned terms to transparency, our findings also offer indirect implications for research into the effects of open government or freedom of information initiatives.

- Study design: Theoretical and empirical studies were included in our analysis because we are interested in rendering a 
comprehensive accounting of how public sector transparency is understood, what is believed to do, and what it has been found to do. Moreover, for empirical studies, we did not discriminate according to method of analysis: qualitative case studies were included, as were quantitative studies. While studies that employ transparency as the dependent variable were not screened out, given the objectives of this study, our analysis emphasizes studies that employ transparency as an independent variable.

- Publication year: Studies that were published between 1990 and 2015 were included. We chose this broad time line to capture a wide range of transparency studies, starting from the early inception of this area of inquiry. We acknowledge that there are some older writings that have been highly important in our thinking about transparency (Bentham 1797; Popper 1945). However, the number of studies touching transparency as a research topic before 1990 is very scarce. We would need to exponentially increase our time line to capture a few more studies; therefore, we decided to set the time frame of our systematic review from 1990 through 2015.

- Language: Only records written in English were eligible for incorporation.

- Publication status: Only international peer-reviewed journal articles and books from prominent publishers in fields such as public administration or political science were eligible (i.e., Palgrave Macmillan and Cambridge University Press).

\section{Review Method and Coding}

Following the literature search, a total of 3,678 studies were identified. To identify studies of direct relevance, we then engaged in a selection process following the steps outlined by Liberati et al. (2009). These steps are illustrated in figure 1.

Following the PRISMA screening process, once all records were collected, the studies were screened to identify the records that fulfilled the eligibility criteria. This was done by scanning the abstracts and titles of records included at this stage. Articles that did not match the selection criteria were then removed, as were duplicate studies.

In the second step, we screened studies by reading the full abstract and the full text when necessary. In this step, studies were removed if they were deemed to fall outside the scope of the study. Following this screening process, 187 studies (177 journal articles and 10 books) remained and were included in the systematic review.

For each study included in the review, we developed a data extraction form to summarize articles according to the following criteria: the author(s), publication year, title, journal, analytical method, form of transparency addressed, and effects of transparency. Table 1 outlines the particular criteria in greater detail.

The categorization of forms of transparency requires elaboration. To determine the form of transparency, we drew on previous transparency frameworks (Cucciniello et al. 2014; Grimmelikhuijsen and Welch 2012; Heald 2006). One way of looking at transparency is to apply it to a set of activities that governments perform. Heald (2006) was one of the first scholars to think of transparency as something that occurs as a part of separate events and processes of government. Later, this framework was adapted to make it more suitable for empirical study by Grimmelikhuijsen and Welch (2012), who identified three broad points at which government determines the level of transparency: (1) transparency of decision-making processes, (2) transparency of policy content, and (3) transparency of policy outcomes or effects. This is what we classify in this study as "transparency of activities."

A second way of classifying forms of transparency is according to the area of government (object) that it elucidates (Cucciniello et al. 2014). This method of classifying forms of transparency does not necessarily focus on a specific activity but rather on a set of activities associated with a certain object. Cucciniello and Nasi (2014) set out three widely investigated objects of transparency: financial or budget transparency, administrative transparency, and political transparency. Budget transparency refers to the disclosure of information about the financial situation of a government and outlines how public actors use the financial resources they are allocated (building on Pina, Torres, and Royo 2010). Administrative transparency is the disclosure of information from the administration or bureaucracy pertaining to the activities of public organizations, mission, and operations (Cucciniello et al. 2014). Finally, political transparency relates to the openness of elected bodies such as parliaments or local councils and refers to information pertaining to political representatives (Cucciniello, Nasi, and Valotti 2012).

We acknowledge that the classification used in this article (administrative, political, and budget) is not perfect and that these "objects" of transparency are intertwined and can overlap. However, in the literature, the distinction between administrative and political transparency has become accepted (see, e.g., Meijer, 't Hart, and Worthy 2015). Moreover, the reason we treat budget (or financial) transparency separately is that there has been a vast stream of publications that have focused solely on this type of transparency (Bastida and Benito 2007; Benito and Bastida 2009; Bolívar, Pérez, and López-Hernández 2015; Caamaño-Alegre et al. 2013; Heald 1995), meaning that this welldeveloped stream of transparency literature typically treats budget transparency as something separate from the political or administrative forms of transparency. In reality, however, financial transparency is interconnected with both the political and administrative realms.
The methods of classifying transparency (object versus activity) outlined here offer alternative perspectives on how to systematically examine the overarching concept of government transparency, yet they are not mutually exclusive. For instance, budget transparency may encompass various activities, such as decision making about the budget, certain policies to improve budget balance, and the effects of this policy. Conversely, decision-making transparency could regard various objects, such as the administrative, political, or financial. Although we realize that every framework requires some arbitrariness in borderline conditions, we think these established frameworks help identify what the literature on transparency has been focusing on and, consequently, what kinds of objects or activities lack attention.

Coding of the studies included for analysis was carried out by each of the coauthors to ensure agreement in the way articles were 


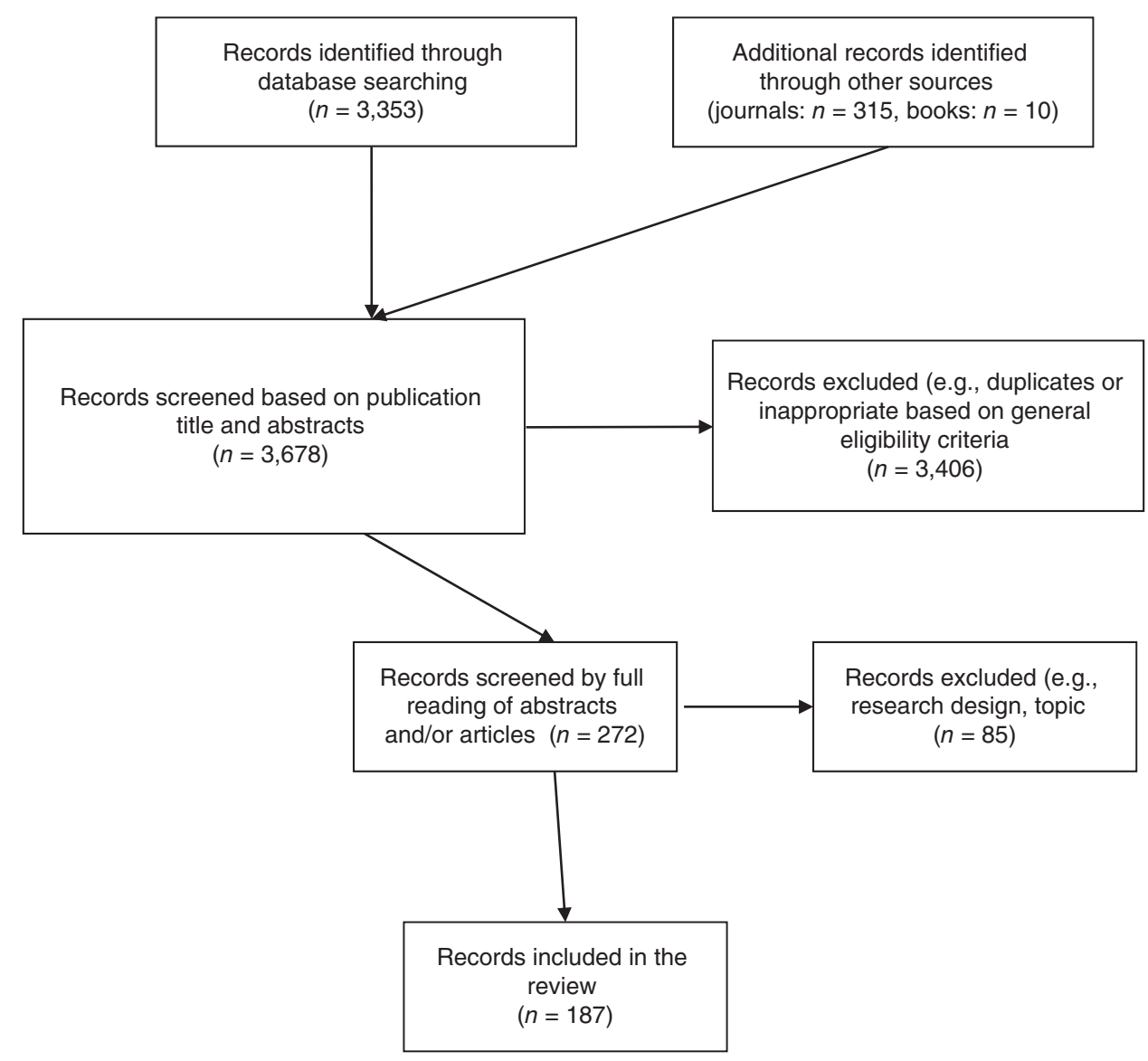

Figure 1 PRISMA Flowchart for Database Searches and Retaining Studies

coded. The coding scheme was discussed by the authors during several Skype calls in order to guarantee consistency in coding by way of agreeing on a common way of coding specific categories. Specifically, having each of the authors code the articles in the analysis ensures reliability in terms of how each study was coded according to the form of transparency addressed, the research design that was employed, and the effect of transparency that was identified. Results of the coding were aggregated into a single spreadsheet and discussed during regular group meetings. In instances in which questions arose over why an article was coded a particular way, all authors reviewed the article in question and came to a consensus on the categorization of the article.

\section{Results of the Systematic Review}

The 177 articles included in the systematic review (of 187 studies, 10 were monographs) were published in 69 peer-reviewed international journals. For a complete list of the journals used, please refer to online appendix 3. The five outlets that published the most articles on the topic of government transparency were Government Information Quarterly (25), International Review of Administrative Sciences (13), Information Polity (11), Public Administration Review (11), and Public Administration (10). This indicates that the main thrust of government transparency research can be found in more generic public administration journals (International Review of Administrative Sciences, Public Administration Review, Public Administration) and in journals that span the boundaries of informational sciences and public administration (Government Information Quarterly, Information

\begin{tabular}{|c|c|}
\hline Category & Extraction \\
\hline $\begin{array}{l}\text { Author, publication } \\
\text { year, title, journal }\end{array}$ & $\begin{array}{l}\text { This basic information was extracted from the title page of } \\
\text { the article. }\end{array}$ \\
\hline Methods & $\begin{array}{l}\text { We used several classifications extracted from the abstract: } \\
\text { Theoretical or empirical } \\
\text { Qualitative, quantitative, experimental }\end{array}$ \\
\hline $\begin{array}{l}\text { Form of } \\
\text { transparency }\end{array}$ & $\begin{array}{l}\text { Based on frameworks by Heald (2006), Cucciniello et al. } \\
\text { (2014), and Grimmelikhuijsen and Welch (2012) we } \\
\text { classified three main "objects of transparency" and } \\
\text { three main "activities of transparency" } \\
\text { - Objects: administrative, political, budget transparency } \\
\text { - Activities: Decision making, policy making, policy } \\
\text { outcome } \\
\text { This information was extracted from the abstract or full text. }\end{array}$ \\
\hline $\begin{array}{l}\text { Outcomes of } \\
\text { transparency }\end{array}$ & $\begin{array}{l}\text { We used two broad classifications: effects on citizens and } \\
\text { effects on government. Within these broad categories } \\
\text { we specified the effects as follows: } \\
\text { - Effects on citizens: legitimacy, participation, trust in } \\
\text { government, satisfaction } \\
\text { - Effects on government: accountability, corruption, } \\
\text { performance, decision-making process, financial } \\
\text { management, collaboration between governments. }\end{array}$ \\
\hline
\end{tabular}

Polity). In the next section, we will discuss how government transparency is defined in the body of literature.

\section{Describing the Corpus of Literature}

Definitions: Integrating Two Types of Definitions. The definitions of transparency offered by the articles included in our review can be 


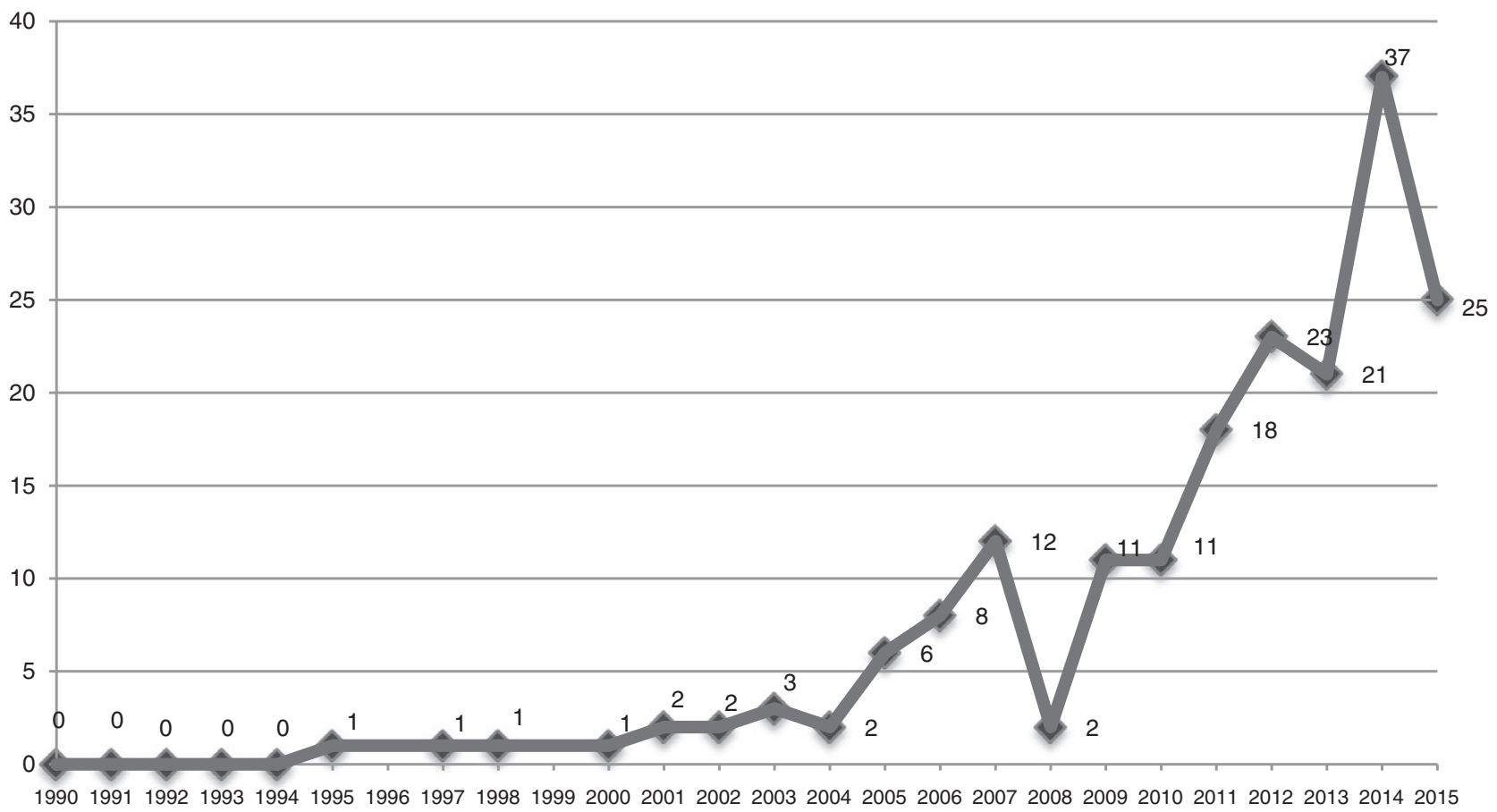

Figure 2 Transparency Research, 1990-2015

grouped into two categories: the first category of definitions focus on information availability and the second on the flow of information.

In terms of articles that define transparency according to the availability of information, three particular points of emphasis are identified. The first relates to the availability of information about decision processes regarding budgetary matters, political issues, and general administrative procedures (e.g., de Fine Licht 2011, 2014; Meijer, Curtin, and Hillebrandt 2012; Pina, Torres, and Royo 2010). The second relates to the availability of information detailing the operational aspects of an organization (e.g., Tejedo-Romero and Araújo 2015). The third relates to the availability of information discussing government performance (Cuadrado-Ballesteros 2014; Grimmelikhuijsen and Meijer 2014).

Definitions that center on the flow of information are, at their core, relational in the sense that they consider stakeholders' access to various types of government information (Heald 2006). Accordingly, these definitions tend to assess transparency from four perspectives: (1) transparency inward (when those outside can observe what is going on inside the organization), (2) transparency outward (when those inside an organization can observe what is happening outside the organization), (3) transparency upward (from subordinates to superiors), and (4) transparency downward (from superiors to subordinates) (Heald 2006, 2012). All four forms of transparency can exist simultaneously; however, the literature tends to focus on a single perspective. Moreover, while there is research employing each of the definitional perspectives, the studies included in our analysis place a strong emphasis on the outward observability of public organizations.

These perspectives on defining transparency are complementary in that the availability perspective emphasizes the breadth of access to government information, whereas the flow of information perspective takes into consideration who has access to information. Together, they help piece together an overarching definition of transparency that explains how much information is accessible to whom. Moreover, emphasis placed on outward transparency identified in the flow of information perspective suggests that much of the existing government transparency research views external stakeholders (e.g., citizens) as the primary audience of government information. We can use the perspectives in order to furnish a single broad definition of government transparency that accounts for both perspectives offered in the literature: "the extent external actors are afforded access to information about the way public organizations operate" (Porumbescu 2015a; see also Grimmelikhuijsen et al. 2013; Meijer 2013).

Transparency over Time: A Strong Rise in Three Distinct Periods of Research. Figure 2 reveals tremendous growth in public administration research focusing on transparency from 1990 to 2015. Indeed, from 1990 to 2000 , a total of four articles addressing the topic of government transparency were published. This small number of articles is distributed across three different fields of study: public administration (Heald 1995), e-government (Perritt and Rustad 2000), and international studies (Birkinshaw 1997; Mitchell 1998). Thus, while transparency has been a topic of long-standing importance to the field of public administration, prior to 2001, this topic appears to have received very little attention from scholars. Following 2001, we see a slight uptick in articles published on this topic followed by a dramatic increase in 2007 as the number of publications on transparency more than tripled. Finally, a second large increase is also apparent in 2011, when the number grew from 11 articles published on the subject in 2010 to 18 in 2011 and peaking at 37 publications in 2014. The shifts outlined in figure 1 delineate three distinct trends in transparency research over the 20-year time span examined in this study: a seminal period with a few publications spanning 1990 to 2002, a period in which transparency research grew cautiously and formed a substantive contribution in various fields from 2004 to 2010, and rapid growth period from 2011 to the present. 
Together, these trends demonstrate a broad span of authors publishing on the topic, showing that the waxing of transparency research is attributable to widespread interest and not just the result of a handful of productive scholars. A final indication of the growing breadth of scholarly interest in transparency, which coincides with the rapid rise in publications (since 2011), is the first Global Conference on Transparency Research, which was organized by Rutgers University in Newark in 2011, followed by conferences in Utrecht (2012), Paris (2013), and Lugano (2015). Cumulatively, these trends illustrate a rapidly growing community of scholars interested in the topic of public sector transparency.

\section{Geographic Context: Predominant Focus on North America and} Europe. While transparency research has grown rapidly over the course of the past 25 years, it is also important to understand which areas are receiving the most attention.

Table 2 illustrates the distribution of research on transparency by region between 1990 and 2015. Nearly half of all the transparency research included in this study is concentrated in two regions: North America and Europe. Additionally, nearly one-third of all transparency research articles examined in this study are cross-national comparisons. However, many of these cross-national comparisons tend to focus on more developed nations (e.g., OECD nations). On the other hand, there is a considerable deficit in transparency research focusing on international organizations, Latin American, African, and Asian contexts.
The third explanation is that there are significant barriers to conducting in-depth research on the topic of transparency in these regions. For example, regimes may be unwilling to open themselves up to scrutiny of scholars, they may lack developed or stable practices and laws pertaining to transparency that facilitate research on the topic, or there may be language hurdles that inhibit research by individuals outside of the region. Therefore, a key challenge that accompanies this regional bias in research on transparency is that we are unaware of the extent to which the claims and findings identified in primarily Western contexts generalize to other contexts.

Research Methods: Balance between Qualitative and Quantitative Studies. Figure 3 illustrates the way the studies included for analysis have examined transparency over time. As can be seen, there are nearly five times more empirical assessments of transparency than conceptual analyses (157 empirical studies versus 30 conceptual). However, this empirical emphasis in transparency research is relatively recent, with a large increase in empirical studies dealing with the topic of transparency beginning in 2011 (50 empirical studies before 2011 versus 107 after). Given that much of the earlier work on transparency was conceptual, it could be that these early pieces provided theoretical grounding for the empirical work in later years. Furthermore, the conceptual and empirical strands of research on transparency are now occurring at two distinct rates, with empirical research demonstrating sustained growth and conceptual discussions of transparency remaining relatively stagnant over time.
The distribution of transparency research across regions that we have identified is not uncommon for public administration (see Ritz, Brewer, and Neumann 2016 for a similar distribution for publications on public service motivation). The relative lack of attention paid to transparency in Latin American, African, and Asian contexts may be explained in three ways, although the data collected for this study do not offer direct insight into which is most likely. The first is that scholars who write about transparency in these regions tend to publish their research in non-English-language academic journals, which would result in an underrepresentation of transparency research dealing with these regions.

The second possibility is that there is a genuine lack of research on this topic pertaining to these regions. These regions are home to a range of developing nations, meaning that the idiosyncrasies of the administrative contexts in these regions lead scholars to focus their research efforts on other issues.

Table 2 Transparency Studies by Geographic Context

\begin{tabular}{lcc}
\hline Country (Where Study Was Conducted) & $\begin{array}{c}\text { Number of } \\
\text { Articles }\end{array}$ & $\begin{array}{c}\text { Percentage of } \\
\text { Articles }\end{array}$ \\
\hline North America & 35 & $21 \%$ \\
Europe & 51 & $31 \%$ \\
Asia & 18 & $11 \%$ \\
Latin America & 8 & $5 \%$ \\
Africa & 2 & $1 \%$ \\
Cross national comparative & 46 & $28 \%$ \\
International organizations & 4 & $2 \%$ \\
Total & 164 & $100 \%$ \\
No geographic context specified & 23 & \\
\hline
\end{tabular}

Given the rate of growth in empirical studies, it is important to consider the research methods being used. As figure 4 reveals, there is a balance between quantitative and qualitative studies, which is distinct from the findings of systematic literature reviews dealing with other areas of public administration scholarship in that they demonstrate an emphasis on either qualitative or quantitative research (see De Vries, Bekkers, and Tummers 2015; Ritz, Brewer, and Neumann 2016; Tummers et al. 2015; Voorberg, Bekkers, and Tummers 2014). Also of note is the subtle trend toward the use of experiments in transparency research, which, while not yet at the same level of use as strictly qualitative or other quantitative methods, demonstrates promise for increasing over time.

Thus, all told, the empirical methods used to examine public sector transparency demonstrate considerable diversity given the relative lack of attention this topic receives when compared research areas that have received more attention. Moreover, while conceptual studies do not appear to be increasing much over time, their presence in the literature may also indicate that there is lingering uncertainty over what transparency is and what it should do.

\section{Gaining Insight into Our Research Questions Question 1: What Forms of Government Transparency Are} Identified in the Literature? Transparency is a broad term that can be used to describe the prevalence of information pertaining to any number of aspects related to government. Because of the diversity of information that can enhance transparency, different frameworks have been identified to specify the precise aspect of governmental operations being examined. Here, we discuss the different forms of 


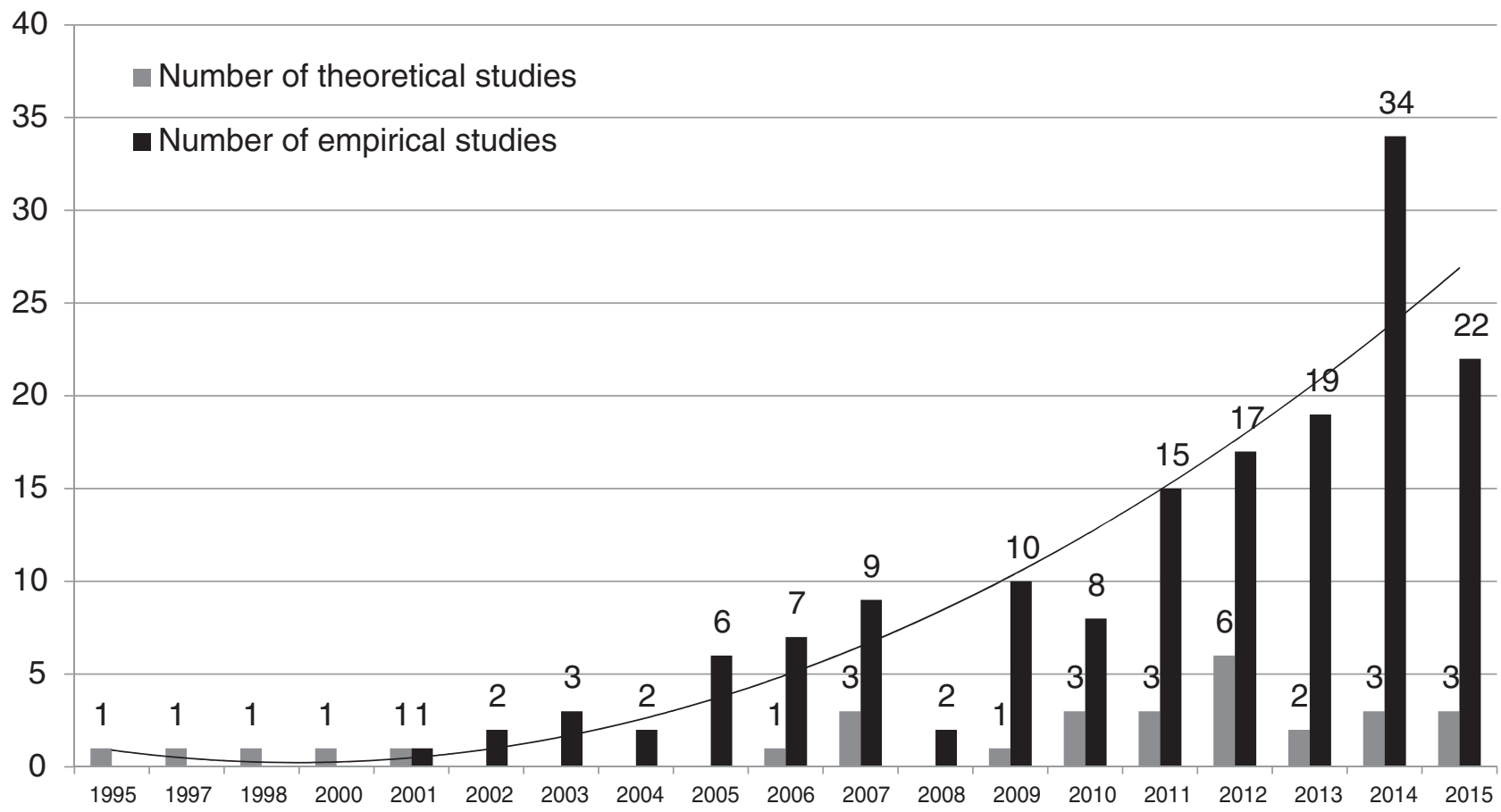

Figure 3 Analytical Methods Used in Transparency Research by Year

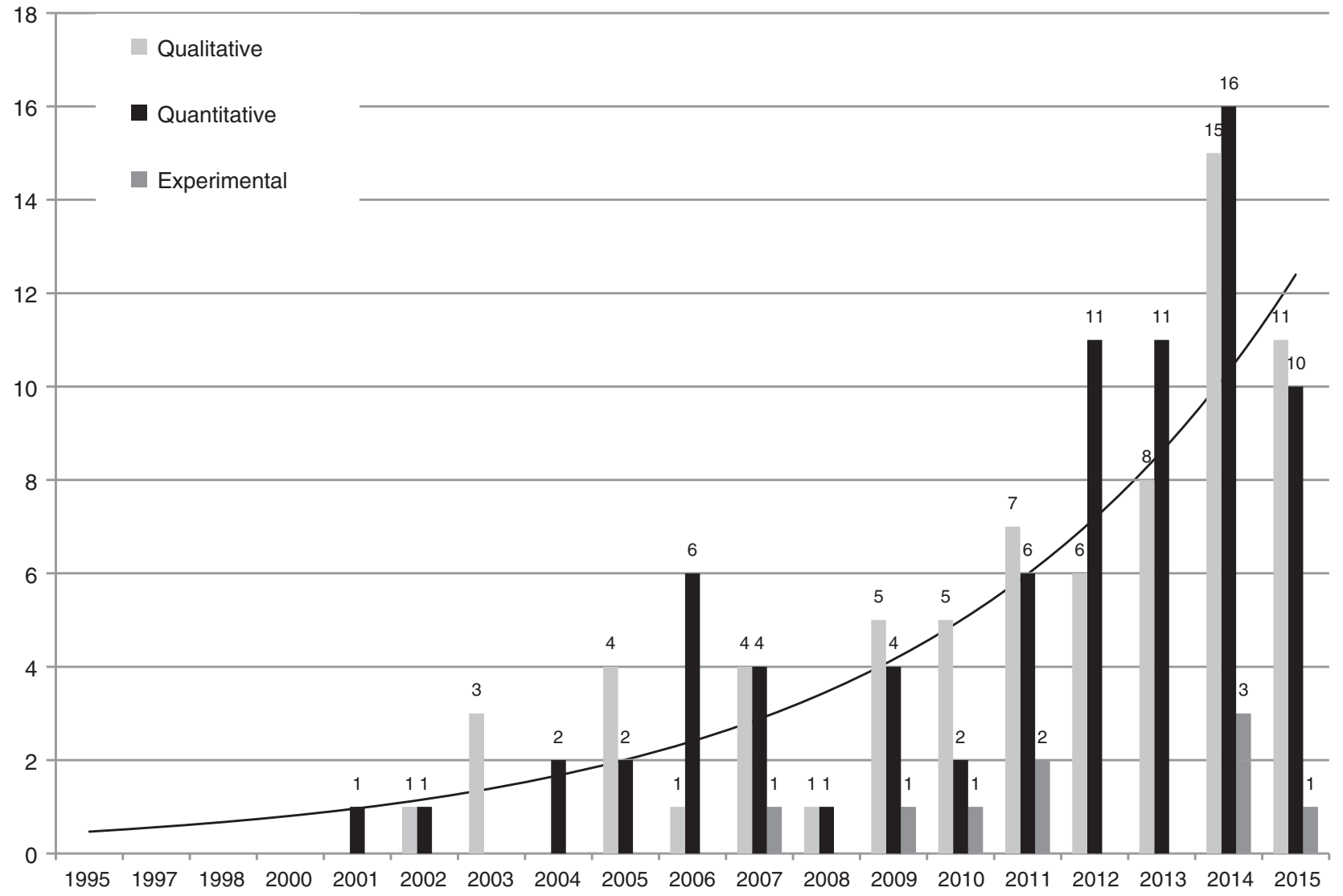

Figure 4 Types of Empirical Studies by Year

38 Public Administration Review • January|February 2017 
transparency that have been identified in the public administration literature as well as the amount of attention that has been paid to those different forms of transparency (see the methods section for an elaboration on this). To facilitate this discussion, we categorize forms of transparency discussed in the literature according to the objects of transparency and transparency of public sector activities frameworks overviewed earlier (Cucciniello et al. 2014; Grimmelikhuijsen and Welch 2012; Heald 2006). The activities and object classifications offer two perspectives on how to think about government transparency. However, they are not mutually exclusive.

Table 3 shows that, of the studies included in this article, 102 identify and discuss three distinct forms of transparency: administrative transparency, political transparency, and budget transparency. These forms of transparency fall under the objects of transparency category. Among these three forms of public sector transparency, a great deal of attention is paid to budget transparency (47 studies) — how public organizations use their money and measures they took to public disclose this financial information. On the other hand, there is much less emphasis placed on administrative transparency (24 studies). This form of transparency discusses the structural features and procedures of public organizations as well as the different functions they carry out. There have also been a number of articles on the topic of government transparency that discuss political transparency. These studies explain political transparency as information about elected officials, ranging from their salary to their involvement in various decision-making processes (Cucciniello and Nasi 2014). Together, forms of transparency grouped under the transparency of objects category typically focus on explicating administrative processes and costs.

Table 3 also reveals that an additional 23 studies included in our analysis identify three more forms of transparency: decisionmaking transparency, policy transparency, and policy-outcome transparency. These three forms of transparency can be placed under the transparency of activities category. Among the studies in this category, there are very few that examine policy transparency-information that discusses what a particular policy intends to do, how it is doing it, and why it is doing it. However, there are twice as many studies that discuss decision-making transparency-information about the debate and discussions that led to the adoption of a particular policy. A total of eight studies address policy outcome transparency, which is information that explains how successful a policy was in fulfilling its objectives

Table 3 Forms of Transparency Identified in the Literature

\begin{tabular}{lcc}
\hline Transparency Type & Number & Percent \\
\hline Object of transparency $^{\text {Administrative }}{ }^{\mathrm{a}}$ & 102 & $57,6 \%$ \\
Political $_{\text {Budget }}$ & 24 & $13,6 \%$ \\
Transparency of activities & 31 & $17,5 \%$ \\
Decision making & 47 & $26,6 \%$ \\
Policy & $\mathbf{2 3}$ & $\mathbf{1 3 , 0 \%}$ \\
Policy outcome & 10 & $5,6 \%$ \\
Unspecified/general & 5 & $2,8 \%$ \\
Total $^{b}$ & 8 & $4,5 \%$ \\
\end{tabular}

aThis also includes journal articles focusing on organizational and administrative types of transparency.

bonly journal articles are included in this part of the analysis. (performance). When taken together, the forms of transparency grouped under the transparency of activities category tend to address the way transparency is impacting citizens' relationships with their government by demonstrating to citizens the steps their government takes in order to ensure their well-being. An interesting observation is that, when compared with research on the objects of transparency, there is far less attention paid to forms of transparency that fall under the transparency of activities category.

Finally, a large proportion of studies in our analysis—nearly 30 percent—did not address a particular form of transparency. Rather, these studies referred to transparency in a general sense. For example, many of the e-government studies that examined transparency broadly defined the topic, without specifying a particular area of emphasis (e.g., Meijer 2009) or explained that their focus was on how the content on e-government websites contributed to greater transparency (e.g., Pina, Torres, and Royo 2009).

Questions 2 and 3: What Outcomes Are Attributed to Government Transparency and What Does Government Transparency Tend to $B e(U n)$ Successful in Achieving? The preceding sections have offered insight into methods used to examine transparency and points of emphasis in transparency research. In this section, we provide an overview of the goals of transparency and evaluate the extent to which previous research has found that transparency helps achieve those goals. To facilitate this discussion, we consider the goals of transparency from two broad perspectives: effects on citizens and effects on government. The goals of transparency and the perspective they are assigned to are illustrated in table 4.

An initial observation from table 4 is that transparency has been tied to a broad array of goals. The majority of the goals (5) fall under the government perspective and consider ways that transparency can improve some aspect of government performance. Four citizencentric goals are identified. While there is a slight disparity in the number of goals associated with the two perspectives, there are comparable numbers of studies assessing both broad sets of goals-a total number of 45 studies look at goals associated with citizens, whereas 47 studies look at goals associated with government.

Looking at the distribution of research assessing various goals offers additional insight into the aforementioned research trends (see online appendix 2). Studies during the seminal period (period 1) of transparency research typically did not explicitly focus on a particular outcome of transparency. Indeed, from 1990 to 2002, only six studies attempted to discuss antecedents to and outcomes of more transparency. However, in period 2, a sustained increase in interest in the determinants and outcomes of greater transparency is readily observable. Moreover, this growth appears to be more concentrated on government-oriented goals than citizen-oriented goals. Period 3 demonstrates a broadening of research across the different goals of transparency as research on government-oriented goals remained steady while research on citizen-oriented goals grew. Thus, over time, research into the effects of transparency appears to have expanded into a number of new areas. While this study does not explicitly account for research on the antecedents of transparency, it is also interesting to note the large growth in research on the determinants of transparency (more than a 100 percent increase when compared with period 1). 
4 Transparency Outcomes in the Literature

\begin{tabular}{|c|c|c|c|}
\hline Effects on... & $\begin{array}{c}\text { Theoretical } \\
(\%)\end{array}$ & Empirical (\%) & Effect \\
\hline \multicolumn{4}{|l|}{...citizens } \\
\hline \multirow[t]{4}{*}{ Legitimacy } & 0 & $2(33.3 \%)$ & Positive \\
\hline & 0 & 0 & Negative \\
\hline & $2(33.3 \%)$ & $2(33.3 \%)$ & Mixed \\
\hline & 0 & 0 & No effect \\
\hline \multirow[t]{4}{*}{ Citizen participation } & 0 & $9(60 \%)$ & Positive \\
\hline & 0 & $1(6.7 \%)$ & Negative \\
\hline & 0 & $2(13.3 \%)$ & Mixed \\
\hline & 0 & $3(20 \%)$ & No effect \\
\hline \multirow[t]{4}{*}{ Trust in government } & 0 & $7(38.9 \%)$ & Positive \\
\hline & $1(5.6 \%)$ & $3(16.6 \%)$ & Negative \\
\hline & $2(11.1 \%)$ & $4(22.2 \%)$ & Mixed \\
\hline & 0 & $1(5.6 \%)$ & No effect \\
\hline \multirow[t]{4}{*}{ Satisfaction } & 0 & $4(66 \%)$ & Positive \\
\hline & 0 & 0 & Negative \\
\hline & $1(17 \%)$ & $1(17 \%)$ & Mixed \\
\hline & 0 & 0 & No effect \\
\hline Total citizens & 6 & 39 & \\
\hline \multicolumn{4}{|l|}{...government } \\
\hline \multirow[t]{4}{*}{ Accountability } & $3(15 \%)$ & $6(30 \%)$ & Positive \\
\hline & 0 & 0 & Negative \\
\hline & $1(5 \%)$ & $6(30 \%)$ & Mixed \\
\hline & 0 & $4(20 \%)$ & No effect \\
\hline \multirow[t]{4}{*}{ Less corruption } & 0 & $7(100 \%)$ & Positive \\
\hline & 0 & 0 & Negative \\
\hline & 0 & 0 & Mixed \\
\hline & 0 & 0 & No effect \\
\hline \multirow[t]{4}{*}{ Performance } & $1(7.7 \%)$ & $5(38.5 \%)$ & Positive \\
\hline & $1(7.7 \%)$ & 0 & Negative \\
\hline & $2(15.4 \%)$ & $3(23 \%)$ & Mixed \\
\hline & 0 & $1(7,7 \%)$ & No effect \\
\hline \multirow[t]{4}{*}{ Decision-making process } & 0 & 0 & Positive \\
\hline & 0 & $1(50 \%)$ & Negative \\
\hline & 0 & $1(50 \%)$ & Mixed \\
\hline & 0 & 0 & No effect \\
\hline \multirow[t]{4}{*}{ Financial management } & 0 & $4(80 \%)$ & Positive \\
\hline & 0 & 0 & Negative \\
\hline & $1(20 \%)$ & 0 & Mixed \\
\hline & 0 & 0 & No effect \\
\hline Total government & 9 & 38 & \\
\hline Grand total & 15 & 77 & \\
\hline
\end{tabular}

Notes: Percentages in the table are calculated based on the total number of theoretical and empirical studies. Studies in the "mixed effect" category offer evidence of both positive and negative relationships between transparency and a particular outcome of interest. Studies in the "negative effect" category offer evidence of a negative relationship between transparency and an outcome of interest. Studies in the "positive effect" category offer evidence of a positive relationship between transparency and an outcome of interest. Finally, 58 studies focused on explaining government transparency as the dependent variable (not included in table).

Empirical research that examines the success of transparency in achieving the different goals reveals a complex picture in that there appear to be few instances where existing research is unanimous. We can start by assessing these results across the broad citizen-oriented and government-oriented categories of transparency goals (see table 4). At this level, a key observation is that there is much more inconsistency in results across the citizen-oriented category of transparency goals when compared with the findings of studies grouped under the government-oriented category of goals.

Within the government-oriented category of goals, we find a consistent association between transparency and corruption. Specifically, all seven studies in our assessment suggest that greater transparency results in less corruption. Similarly, a positive relationship between transparency and financial management is consistently supported in the empirical literature.

The utility of transparency in fostering greater accountability of public organizations turns back more mixed results, with six studies identifying a positive relationship between transparency and accountability and six studies offering mixed findings, in that transparency was successful in fostering accountability in some domains examined within a single study but not in others. Further, four studies found no relationship between transparency and accountability at all. In general, the lack of a consistent relationship is attributed to the lack of cultivation of forums that permit citizens to act on the information they are afforded (Lorenço 2015; Porumbescu 2015b). Taken together, it is interesting to note the differences across findings related to corruption and accountability in that accountability is often viewed as an intervening construct in the relationship between transparency and corruption. One explanation for this difference is that greater transparency, at least up to a point, can actually foster internal adjustments that result in improved organizational performance (Prat 2005). Studies that assess the link between transparency and different aspects of organizational performance do offer tentative support, with more than half of the empirical studies finding support for a positive relationship between performance and transparency (56 percent) and the remaining studies (44 percent) finding support in some domains but not in others (e.g., Meijer, 't Hart, and Worthy 2015).

Findings under the citizen-oriented category of transparency goals, while generally positive, demonstrate greater inconsistency across studies. This point is perhaps most salient for research that examines the relationship between transparency and trust in government. One explanation is that there is wide variety in how citizens view government transparency (Piotrowski and Van Ryzin 2007), and this makes the effects of transparency on citizen-centered outcomes much more dependent on a specific context.

It is also interesting to note that, among the studies examining the relationship between transparency and trust in government, findings differ according to the method of analysis_-experiments and case studies tend to turn back negative or mixed findings, whereas studies drawing on survey data uncover more positive relationships. This point extends to studies that examine the relationship between transparency and perceptions of legitimacy as well-two experimental studies assessing this relationship turn back mixed findings, whereas studies drawing on observational data find a positive relationship.

The use of experiments included in our analysis primarily focus on the relationships between transparency, trust in government, and legitimacy. Therefore, we are unable to consider whether analytical methods are relevant to understanding variation in findings elsewhere. Findings related to the potential of transparency to bolster citizen satisfaction and participation tend to be more consistent and positive. With respect to satisfaction, 80 percent (4 studies) of the empirical studies examined found evidence of a positive relationship, whereas 
the remaining 20 percent ( 1 study) turned back mixed findings. For participation, a similar pattern is uncovered, with 60 percent of the studies (9) suggesting greater transparency fosters greater participation and the remaining 40 percent falling into the mixed (13.3 percent or 2 ), negative (6.7 percent or 1 ), or no effect (20 percent or 3) categories. As was the case with the varied findings from studies assessing the relationship between transparency and accountability, these differences may be attributable to forums (or lack thereof) used by citizens to engage government.

One final note here is that the bulk of the literature included in our analysis does not attempt to match particular forms of transparency to specific outcomes. Rather, studies attempt to link transparency, broadly construed, to particular objectives, such as fostering greater trust, satisfaction, or accountability. One notable exception, however, relates to budget transparency. The studies included in our analysis assessed the implications of this form of transparency for various goals more than any other particular form of transparency identified in the literature. One reason for this may be that the (potential) effects of budget transparency are more readily apparent than the effects of other forms of transparency.

\section{Discussion}

Our analysis illustrates sustained and widespread growth in research on the topic of transparency in public administration. Factors contributing to the growth of academic interest in the topic of transparency appear to stem from shifts in the global, national, and local environments that public sector organizations operate within. For instance, the multilateral Open Government Partnership launched in 2011, the Open Government Directive issued by President Barack Obama in 2009, and enhanced transparency regulations in the European Union (Hillebrandt, Curtin, and Meijer 2014) all contributed to a push for transparency policies and eventually research.

All told, the literature reviewed in this study identified and reviewed three forms of public sector transparency focused on a certain "object"_administrative transparency, political transparency, and budget transparency — and three types focused on "activities" decision-making transparency, policy transparency, and policy outcome transparency. Our analyses have also uncovered a range of outcomes that are expected to result from enhancing different forms of transparency, which cluster into government-centric and citizencentric categories. However, while the studies included in our analysis have identified distinct forms of transparency and distinct goals of transparency, the body of literature tying particular forms of transparency to particular goals remains underdeveloped.

Our review illustrates that there are some very clear benefits of transparency, particularly when it comes to government-centric goals. For example, greater transparency appears to consistently improve the quality of financial management and reduce levels of public sector corruption. On the other hand, the relatively large number of mixed results for core transparency goals such as trust, legitimacy, and accountability suggests that other benefits of greater transparency are less clear-cut.

One factor that contributes to some of the variation in findings across studies is the method of analysis. Indeed, the relationships between transparency and trust in government or legitimacy appear be contingent on whether the study drew on observational data or experimental data. Furthermore, it is likely that contextual conditions matter as well. In other words, under some circumstances, transparency may positively contribute to, for instance, accountability, whereas it does not in another situation. These contextual conditions are hardly explored in a systematic empirical manner, but our review shows that they merit attention. Some contextual conditions that bear upon the effect of transparency identified to date include national cultural values (Grimmelikhuijsen et al. 2013), the type of policy issue at stake (de Fine Licht 2014), the form of government (Michener 2015), and the method used to enhance transparency (Porumbescu 2015a). This point is strengthened by the fact that our analysis illustrates that there were no goals that transparency consistently failed to achieve. Therefore, debates over the merits of enhancing transparency must start, in large part, from a premise that the effects of transparency are very much a product of the environment in which they are implemented (for excellent illustrations, see Bauhr and Grimes 2014; Lindstedt and Naurin 2010). We address this point in greater detail in the following section.

Together, the findings of this systematic literature review illustrate just how far transparency research has come over the course of the past few decades. Whereas government transparency has historically been proffered as a solution to the gamut of challenges that governments face, the rapidly growing body of research on this topic is helping to qualify such claims. In doing so, this literature is gradually piecing together a more accurate understanding of the transformative potential that accompanies enhancements to transparency. Moreover, and perhaps more importantly, this developing body of literature draws our attention to further research that is necessary to better understand what we can do to improve the way in which transparency is used to address various issues that are faced by the state. To this end, while the inconsistency in findings assessed in this study may be viewed as disappointing and a mark against the transformative potential of transparency, we argue that this variation, in large part, helps establish a framework for a rich transparency research agenda in the years to come.

\section{Ways Forward: Charting Transparency Research in Years to Come}

The progress made to date charts a course for future research that centers on theoretical and methodological refinement in our understanding of transparency. However, we emphasize that although there are particular points that future research could address, the current body of transparency literature is fairly balanced in terms of focus (about one-third focuses on transparency as a dependent variable, about one-third focuses on effects on governance, and a final third focuses on citizen effects) and methods (half qualitative, half quantitative). Here, we outline four points of refinement to be considered by future research in order to enrich our understanding of the transformative potential of government transparency.

\section{More Systematically Identifying Contextual Conditions That Affect Transparency Outcomes}

In terms of theoretical refinement, there have been few attempts in the extant transparency research, both empirical and conceptual, to understand how particular forms of transparency relate to 
particular objectives. Rather, transparency is often viewed as either being effective at achieving a particular goal or ineffective. However, the effectiveness of different forms of transparency will likely vary according to the outcome it is tasked with achieving. For example, just because one form of transparency may not be effective at bolstering citizens' trust in government does not mean that all forms of transparency are ineffective at bolstering trust in government. This may partly explain the mixed findings of scholars on transparency outcomes such as trust, legitimacy, and accountability. Moreover, variation in terms of transparency's ability to effectuate different outcomes may also be attributed to policy domains. Indeed, this review has also documented instances in which, for instance, the policy domain in which transparency occurs was found to determine its effect on perceived legitimacy of decision making (de Fine Licht 2014). To this end, the role of policy domain in framing the effects of transparency must not be neglected in transparency research. Rather, more systematic exploration of this important contextual condition is needed.

All told, the mechanisms responsible for lending transparency its effects remain poorly understand. As a result, practitioners and scholars are often unable to explain why transparency may succeed in achieving the goals ascribed to it in some situations and fall short in others. Therefore, attempts to introduce greater precision to our understanding of how transparency affects different aspects of government and government's relationships with citizens is essential, especially in light of how (relatively) easy it is for governments today to publicly disseminate information. Indeed, the ease with which governments can now publicly disseminate information makes it even more critical that future research work toward developing a more sophisticated understanding of how to treat certain issues government experiences with certain types of information.

\section{Replicate Studies Using Different Methods}

In terms of methodological refinement, our findings also highlight questions related to external validity and, subsequently, speak to a need for replication studies to refine the external and internal validity of mechanisms that have been identified in previous research using different analytical methods. Transparency has been assessed using a variety of analytical tools, ranging from conceptual analyses, to qualitative analyses, to quantitative analyses, and increasingly, experimental assessments. While the assortment of methods adds a desirable dimension of analytical depth to this field of research, few have questioned the extent to which findings identified using one analytical method will hold when assessed using a different method. In other words, there have been few attempts to gauge external validity through replicating across methods.

Nevertheless, as the findings of our analyses illustrate, there is some initial evidence that method effects loom large in the study of transparency given the discrepancies uncovered between survey based assessments and experimental assessments of the relationships between transparency and trust in government as well as legitimacy. Furthermore, replicating across methods, and in particular replications that draw on experimentation, also provides an opportunity to improve our understanding of the causal mechanisms responsible for transmitting the effects of transparency. At present, there have been few attempts at replication and thus few attempts to assess the external and internal validity of relationships tying transparency to different outcomes of interest, which contributes to uncertainty over just how and when transparency is effective. This uncertainty speaks to questions over just how robust the relationship is between transparency and outcomes and generates broader concerns over the value of transparency.

\section{Replicate Studies across Different Administrative Contexts}

Building on a need to replicate using different methods, we can also consider a need for further refinement along a second dimension, which relates to administrative context (see Meijer, 't Hart, and Worthy 2015). Replicating across various administrative contexts offers an additional means of assessing the external validity of the mechanisms identified in previous research. Our findings illustrate a diffuse surge in empirical research in recent years, which speaks to the fact that a growing body of authors are now vetting claims associated with transparency. Yet, at the same time, what is not brought to bear in the literature is how claims associated with transparency translate across distinct administrative contexts, in terms of either location or policy domains. For instance, our analysis shows that the large majority of publications are based on research in North America or Europe. Very few publications in our review are located in Africa or Latin America (but see, e.g., Michener 2015 for an analysis of transparency in Latin America and Abe 2011 for a study on access to information and accountability in Nigeria). As transparency outcomes are context bound, it is important that transparency practices in these areas of the world receive scholarly attention, too. As such, just as it is important to understand how the effects of transparency vary according to the form of transparency, it is also important to shed light upon how they vary according to context. Doing so will contribute to more effective applications of transparency.

\section{Investigate Neglected Transparency Outcomes}

We found that scholars have devoted attention to a broad array of transparency outcomes. This has led to a diverse but somewhat scattered body of literature. Potential transparency outcomes such as participation, trust in government, and accountability have received considerable attention, with more than 10 studies in each specific area. That said, overall, we still need to know much more to really understand the contextual and societal conditions (see previous suggestions). More precisely, however, some outcomes have seen much less attention than other areas, and researchers have only started to understand how these outcomes relate to transparency.

For instance, the effect of transparency on governance-related outcomes such as decision making and improving (financial) management have seen very little scholarly attention. An exception is a cross-national comparative study by Benito and Bastida (2009), who show that the more information the budget discloses, the less the politicians can use fiscal deficits to achieve opportunistic goals, thus improving financial management.

The same is true for citizen-related goals such as citizen satisfaction and legitimacy. While, on one hand, an attitude such as citizen satisfaction may somehow seem less fundamental then, say, trust in government, on the other hand, it may be an attitude that is more malleable and thus more prone to be influenced by government transparency. One exception here is a study by Hong (2014), who 
found that perceptions of transparency (because of the use of the Internet as a source of government information) were associated with higher levels of satisfaction and, in turn, a more favorable relationship with the city government.

\section{Conclusion}

Taken together, the objectives of this research agenda provide further insight into ways of using government transparency more effectively. While historically the relationship between transparency and various dimensions of the quality of government was often assumed, further research demonstrates that this relationship is complex and nuanced. This level of complexity and nuance has led some to question the value of transparency and its ability to improve the quality of government (see Etzioni 2014; Fukuyama 2015). Despite advancing a number of important claims, such criticisms are ultimately overstated. Transparency, like anything else, is subject to limitations and faulty application - if it is not used correctly, it cannot work properly. Indeed, as our analysis indicates, transparency does work for some goals under certain circumstances but not in others. Therefore, rather than questioning the value of transparency, it makes more sense to focus on assessing where and how it works. In this systematic literature review, we provide an analysis of just how transparency is currently studied and, based on this analysis, outline steps that future research can take to improve the way transparency is understood and used.

\section{Acknowledgments}

Gregory A. Porumbescu's work was supported by National Research Foundation of Korea Grant funded by the Korean Government (NRF-2014S1A3A2044898). Stephan Grimmelikhuijsen acknowledges funding of an NWO (Netherlands Organisation for Scientific Research) grant (no. VENI-451-15-024) that investigates various effects of transparency. The authors consulted a number of experts on the topic of transparency in order to ensure that all relevant journals in the field of public administration, public management and e-government were included. They would like to thank these experts specifically: David Heald, Frank Bannister, Alasdair Roberts, Albert Meijer, Suzanne Piotrowski, Jenny De Fine Licht, Jean Patrick Villeneuve and Greta Nasi for their suggestions. Furthermore, they would would like to thank Albert Meijer and Lars Tummers for their feedback on an earlier version of this paper.

\section{Notes}

1. There have been related systematic analyses of open government (e.g., Meijer, Curtin, and Hillebrandt 2012; Wirtz and Birkmeyer 2015), although this construct, while related, is much broader than transparency As a result, reviews of open government typically aim to conceptualize open government and are less focused on the outcomes/effects of open government.

2. Although the experts provided a great number of relevant studies, all of the recommended studies were eventually included based on our own literature search. This gave us confidence that we used the correct search strategy and search terms.

3. These were the Journal of Public Administration Research and Theory, Public Administration Review, Public Administration, Public Management Review, American Review of Public Administration, International Public Management Journal, International Review of Administrative Sciences, International Journal of
Public Administration, Administration \& Society, Governance, Policy and Internet, Information Polity, and Government Information Quarterly.

\section{References}

References marked with an asterisk $\left(^{*}\right)$ are cited in the article and included in the systematic review. Not all publications included in the review have been cited; a full list of all reviewed articles can be found in online appendix 4 .

*Bastida, Francisco, and Bernardino Benito. 2007. Central Government Budget Practices and Transparency: An International Comparison. Public Administration 85(3): 667-716.

*Bauhr, Monika, and Marcia Grimes. 2014. Indignation or Resignation: The Implications of Transparency for Societal Accountability. Governance 27(2): 291-320.

*Benito, Bernardino, and Francisco Bastida. 2009. Budget Transparency, Fiscal Performance, and Political Turnout: An International Approach. Public Administration Review 69(3): 403-17.

Bentham, Jeremy. 1797. Farming Defended. In Writings on the Poor Laws, edited by Michael Quinn, 276-90. Oxford, UK: Oxford University Press, 2001. *Bertot, John C., Paul T. Jaeger, and Justin M. Grimes. 2010. Using ICTs to Create a Culture of Transparency: E-Government and Social Media as Openness and AntiCorruption Tools for Societies. Government Information Quarterly 27(3): 264-71.

Birkinshaw, Patrick. 1997. Freedom of Information and Open Government: The European Community/Union Dimension. Government Information Quarterly 14(1):

27-49.

*Bolívar, Manuel Pedro Rodríguez, María del Carmen Caba Pérez, and Antonio M. López-Hernández. 2015. Online Budget Transparency in OECD Member Countries and Administrative Culture. Administration \& Society 47(8): 943-82.

*Caamaño-Alegre, José, Santiago Lago-Peñas, Francisco Reyes-Santias, and Aurora Santiago-Boubeta. 2013. Budget Transparency in Local Governments: An Empirical Analysis. Local Government Studies 39(2): 182-207.

Cooper, Harris. 2010. Research Synthesis and Meta-Analysis: A Step-by-Step Approach. Los Angeles: Sage Publications.

*Cuadrado-Ballesteros, Beatriz. 2014. The Impact of Functional Decentralization and Externalization on Local Government Transparency. Government Information Quarterly 31(2): 265-77.

*Cucciniello, Maria, Nicola Bellè, Greta Nasi, and Giovanni Valotti. 2014. Assessing Public Preferences and the Level of Transparency in Government Using an Exploratory Approach. Social Science Computer Review 33(5): 571-86.

*Cucciniello, Maria, and Greta Nasi. 2014. Transparency for Trust in Government: How Effective Is Formal Transparency? International Journal of Public Administration 37(13): 911-21.

Cucciniello, Maria, Greta Nasi, and Giavanni Valotti. 2012. Assessing Transparency in Government: Rhetoric, Reality and Desire. Paper presented at the 45th Hawaii International Conference on Systems Science. Los Alamitos, CA.

*de Fine Licht, Jenny. 2011. Do We Really Want to Know? The Potentially Negative Effect of Transparency in Decision Making on Perceived Legitimacy. Scandinavian Political Studies 34(3): 183-201.

*__ 2014. Policy Area as a Potential Moderator of Transparency Effects: An Experiment. Public Administration Review 74(3): 361-71.

*de Fine Licht, Jenny, Daniel Naurin, Peter Esaiasson, and Mikael Gilljam. 2014. When Does Transparency Generate Legitimacy? Experimenting on a ContextBound Relationship. Governance 27(1): 111-34.

De Vries, Hanna, Victor Bekkers, and Lars Tummers. 2015. Innovation in the Public Sector: A Systematic Review and Future Research Agenda. Public Administration 94(1): 146-66.

Etzioni, Amitai. 2010. Is Transparency the Best Disinfectant? Journal of Political Philosophy 18(4): 389-404. 
- 2014. The Limits of Transparency. Public Administration Review 74(6): 687-88.

Fukuyama, Francis. 2015. Why Is Democracy Performing So Poorly? Journal of Democracy 26(1): 11-20.

*Grimmelikhuijsen, Stephan G., and Albert J. Meijer. 2014. Effects of Transparency on the Perceived Trustworthiness of a Government Organization: Evidence from an Online Experiment. Journal of Public Administration Research and Theory 24(1): 137-57.

${ }^{*}$ Grimmelikhuijsen, Stephan G., Gregory Porumbescu, Boram Hong, and Tobin Im. 2013. The Effect of Transparency on Trust in Government: A Cross-National Comparative Experiment. Public Administration Review 73(4): 575-86.

*Grimmelikhuijsen, Stephan G., and Eric W. Welch. 2012. Developing and Testing a Theoretical Framework for Computer-Mediated Transparency of Local Governments. Public Administration Review 72(4): 562-71.

*Grumet, Jason. 2014. City of Rivals: Restoring the Glorious Mess of American Democracy. Guilford, CT: Globe Pequot Press.

*Heald, David. 1995. Steering Public Expenditure with Defective Maps. Public Administration 73(2): 213-40.

* — 2006. Varieties of Transparency. In Transparency: The Key to Better Governance? edited by Christopher Hood, and David Heald, 25-43. Oxford, UK: Oxford University Press.

*__ 2012. Why Is Transparency about Public Expenditure So Elusive? International Review of Administrative Sciences 78(1): 30-49.

Hillebrandt, Maarten Z., Deirdre Curtin, and Albert J. Meijer. 2014. Transparency in the EU Council of Ministers: An Institutional Analysis. European Law Journal 20(1): $1-20$.

Kosack, Stephen, and Archon Fung. 2014. Does Transparency Improve Governance? Annual Review of Political Science 17: 65-87.

Liberati, Alessandro, Douglas G. Altman, Jennifer Tetzlaff, Cynthia Mulrow, Peter C. Gøtzsche, John P. A. Ioannidis, Mike Clarke, P. J. Devereaux, Jos Kleijnen, and David Moher. 2009. The PRISMA Statement for Reporting Systematic Reviews and Meta-Analyses of Studies That Evaluate Health Care Interventions: Explanation and Elaboration. Annals of Internal Medicine 151(4): W-65-94.

Lindstedt, Catharina, and Daniel Naurin. 2010. Transparency Is Not Enough: Making Transparency Effective in Reducing Corruption. International Political Science Review 31(3): 301-22.

*Lourenço, Rui Pedro. 2015. An Analysis of Open Government Portals: A Perspective of Transparency for Accountability. Government Information Quarterly 32(3): 323-32.

*Meijer, Albert J. 2009. Understanding Modern Transparency. International Review of Administrative Sciences 75(2): 255-69.

*__ 2013. Understanding the Complex Dynamics of Transparency. Public Administration Review 73(3): 429-39.

*Meijer, Albert J., Deirdre Curtin, and Maarten Hillebrandt. 2012. Open Government: Connecting Vision and Voice. International Review of Administrative Sciences 78(1): 10-29.

*Meijer, Albert J., Paul 't Hart, and Benjamin Worthy. 2015. Assessing Government Transparency: An Interpretive Framework. Administration \& Society. Published electronically on August 19. doi:10.1177/0095399715598341.

Michener, Greg. 2015. How Cabinet Size and Legislative Control Shape the Strength of Transparency Laws. Governance 28(1): 77-94.

*Mitchell, Ronald B. 1998. Sources of Transparency: Information Systems in International Regimes. International Studies Quarterly 42(1): 109-30.

*Perritt, Henry H., and Zachary Rustad. 2000. Freedom of Information Spreads to Europe. Government Information Quarterly 17(4): 403-17.
*Pina, Vicente, Lourdes Torres, and Sonia Royo. 2009. E-Government Evolution in EU Local Governments: A Comparative Perspective. Online Information Review 33(6): 1137-68.

*__ 2010. Is E-Government Promoting Convergence towards More Accountable Local Governments? International Public Management Journal 13(4): 350-80.

*Piotrowski, Suzanne J. 2008. Governmental Transparency in the Path of Administrative Reform. Albany: State University of New York Press.

Piotrowski, Suzanne J., and Gregg G. Van Ryzin. 2007. Citizen Attitudes toward Transparency in Local Government. American Review of Public Administration 37(3): 306-23.

Popper, Karl Raimund. 1945. The Open Society and Its Enemies. London: Routledge. Prat, Andrea. 2005. The Wrong Kind of Transparency. American Economic Review 95(3): 862-77.

*Porumbescu, Gregory. 2015a. Does Transparency Improve Citizens' Perceptions of Government Performance? Evidence From Seoul, South Korea. Administration \& Society. Published electronically on July 6. doi:10.1177/0095399715593314.

*_. 2015b. Linking Transparency to Trust in Government and Voice. American Review of Public Administration. Published electronically on October 5. doi: $10.1177 / 0275074015607301$.

Ritz, Adrian, Gene A. Brewer, and Oliver Neumann. 2016. Public Service Motivation: A Systematic Literature Review and Outlook. Public Administration Review 76(3): 414-26.

*Roberts, Alasdair. 2006. Blacked Out: Government Secrecy in the Information Age. New York: Cambridge University Press.

*__ 2012. WikiLeaks: The Illusion of Transparency. International Review of Administrative Sciences 78(1): 116-33.

*_ 2015. Too Much Transparency? How Critics of Openness Misunderstand Administrative Development. Paper prepared for the Fourth Global Conference on Transparency Research, Università della Svizzera Italiana, Lugano, Switzerland, June 4-6.

${ }^{*}$ Tejedo-Romero, Francisca, and Joaquim Filipe Ferraz Esteves de Araújo. 2015. Determinants of Local Governments' Transparency in Times of Crisis: Evidence from Municipality-Level Panel Data. Administration \& Society. Published electronically on September 29. doi:10.1177/0095399715607288.

Tranfield, David, David Denyer, and Palminder Smart. 2003. Towards a Methodology for Developing Evidence-Informed Management Knowledge by Means of Systematic Review. British Journal of Management 14(3): 207-22.

Tummers, Lars L. G., Victor Bekkers, Evelien Vink, and Michael Musheno. 2015. Coping during Public Service Delivery: A Conceptualization and Systematic Review of the Literature. Journal of Public Administration Research and Theory 25(4): 1099-1126.

Voorberg, William, Victor Bekkers, and Lars Tummers. 2014. A Systematic Review of Co-Creation and Co-Production: Embarking on the Social Innovation Journey. Public Management Review 17(9): 1333-57.

*Welch, Eric W., Charles C. Hinnant, and M. Jae Moon. 2005. Linking Citizen Satisfaction with E-Government and Trust in Government. Journal of Public Administration Research and Theory 15(39): 371-91.

Wirtz, Bernd W., and Steven Birkmeyer. 2015. Open Government: Origin, Development, and Conceptual Perspectives. International Journal of Public Administration 38(5): 381-96.

Worthy, Ben. 2010. More Open but Not More Trusted? The Effect of the Freedom of Information Act 2000 on the United Kingdom Central Government. Governance 23(4): 561-82.

\section{Supporting Information}

Supplemental appendices may be found in the online version of this article at http://onlinelibrary.wiley.com/journal/10.1111/ (ISSN)1540-6210. 